\title{
As relações de género no espaço da educação física - a percepção de alunos e alunas
}

\author{
Paula Silva ${ }^{1}$ \\ Paula Botelho Gomes ${ }^{1}$ \\ Silvana Goellner ${ }^{2}$
}

https://doi.org/10.5628/rpcd.08.03.396

\author{
${ }^{1}$ Universidade do Porto \\ Faculdade de Desporto \\ Portugal \\ ${ }^{2}$ Universidade Federal Rio Grande do Sul \\ Escola de Educação Física \\ Brasil
}

\begin{abstract}
RESUMO
O presente estudo pretendeu conhecer e analisar como alunos e alunas classificam e entendem o desenvolvimento das relações de género nas aulas de Educação Física (EF). Foram realizadas 60 entrevistas semi-estruturadas a estudantes (30 de cada sexo) de escolas secundárias do distrito do Porto, com idades compreendidas entre os 15 e os 17 anos. Após o tratamento da informação no programa QSRNVivo, procedeu-se a uma análise indutiva dos dados, ou seja, as categorias de análise não foram impostas num momento precedente mas emergiram dos próprios dados. Findo este processo desenvolveu-se uma análise interpretativa. Os resultados obtidos sugerem que alunos e alunas percepcionam de forma diferente as relações de género nas aulas de EF. Metade do total das alunas entende que as relações não são boas, apresentando algumas queixas relativas aos comportamentos e atitudes dos seus colegas, atitudes que favorecem um desinvestimento nas actividades das aulas de EF.
\end{abstract}

Palavras-chave: relações de género, educação física, aulas mistas

\section{ABSTRACT \\ Gender relations in physical education's classes - students' perceptions}

The purpose of this study was to analyse how students, boys and girls, observe and classify the gender relations in the Physical Education $(P E)$ mixed classes. The analysed data came by from 60 semi-structured interviews from Oporto secondary school students (30 boys and 30 girls). An inductive analysis and interpretation of the data was carried out following the information treatment by the program QSRNVivo. The results suggest that boys and girls analyse differently the gender relations in PE classes. Half of the female students understand that the relations are not good, expressing some complains about their colleagues' behaviours and attitudes which bother them offend them and lead them to a disinvestment in the PE activities.

Key-words: gender relations, physical education, mixed classes 


\section{INTRODUÇÃO}

As pessoas são categorizadas como pertencendo a um ou outro género através dos significados da sua aparência e comportamentos, como, por exemplo, o vestir, o penteado, a maneira como se movimentam e actuam, a sua linguagem corporal. Com efeito, os sinais e os símbolos de género estão em todo lado e, assumidos como formas padronizadas de ser e de estar, não são percebidos como tal. Logo, o género é quase sempre produzido de forma não intencional não é algo que fomos ou somos mas que produzimos ou fazemos ${ }^{(25)}$, assumindo-se como uma questão de aprendizagem, de "trabalho" contínuo, e não uma simples extensão da diferença sexual biologicamente dada ${ }^{(17)}$.

Género, enquanto categoria analítica e processo social, é relacional. Não é construído pelas relações entre homem e mulher na generalidade, porque não há tais pessoas e, portanto, não existem essas relações. Não há relações de género entre homem e mulher num qualquer grupo particular configuradas unicamente pelos homens e mulheres desse grupo elas também o são pelo modo como homem e mulher são definidos por outras raças, classes ou culturas nesse contexto. As relações de género, em toda a situação histórica particular, são sempre construídas pela ordem hierárquica das relações sociais em que 'mulher' ou 'homem' participam(19), o que implica uma análise das relações de género enquanto efectivas relações de poder. O género deve ser perspectivado como uma construção histórica das relações de poder entre homens e mulheres, e deve contemplar definições plurais de masculinidade e feminilidade ${ }^{(7)}$. Assim, como constructo social, o conceito de género varia ao longo do tempo e de cultura para cultura, e reporta-se às relações sociais nas quais pessoas e grupos actuam(8).

As relações de género, pelo quanto nos é dado a conhecer, têm sido, com maior ou menor predominância, relações de dominação. Jane Flax ${ }^{(13)}$, numa perspectiva de relações sociais, afirma que homens e mulheres são ambos prisioneiros do género embora de distintos mas interrelacionados modos. Com efeito, enquanto relações sociais de poder, as relações de género caracterizam-se por formas de dominação permanentemente desafiadas, contestadas e refeitas, por um processo que inclui cedências e negociações e que conduz a novas formas legitimadas de dominação. A posição construcionista, tal como as teorias da socialização, apresenta vários problemas por pressupor uma dicotomia de género incontornável, a qual assenta numa diferença biológica de cariz essencialista. Entre outros problemas, deixam-nos com as categorias dicotómicas de homens e mulheres, com uma visão das relações entre estas duas categorias em termos de entidades polarizadas e fixas, e inviabilizam uma visão dinâmica, polifacetada das masculinidades e feminilidades, inclusive o uso destes termos como operadores metafóricos para o poder e a diferenciação ao nível de sexo e género, mas não só(34).

O desporto foi identificado como um importante espaço na construção e incorporação de relações de género( ${ }^{(30,31)}$, e não é de ignorar, nem tão pouco de desprezar, que o desporto, pela sua elevada importância em muitas sociedades, tem o potencial de se constituir como agente na mudança da ordem de género(12, 21, 32).

O enquadramento do desporto na escola afigura-se como tarefa incontornável, que, embora permanentemente inacabada, deve, antes de tudo, nortear-se, como sugere Jorge Bento(2), por uma visão do desporto enquanto fenómeno em transformação no sentido da diversidade e pluralidade. No entanto, a importância da disciplina de EF no currículo escolar é, ainda hoje, algo fundamental a relembrar e continua presente nas reflexões de produções nacionais e internacionais no âmbito da pedagogia do desporto. A história da EF (de quase dois séculos) é a história da permanente necessidade de fundamentar, legitimar e alicerçar o seu lugar, a sua relevância e presença no seio das disciplinas escolares. É a única disciplina que visa preferencialmente a corporalidade, e, dessa forma, permite que os/as estudantes aprendam a viver em sintonia com o seu corpo - por se distinguir no concernente à sua tarefa educativa primordial, ao educar, formar, socializar e possibilitar experiências a partir do corpo $(3,4)$.

Parece fundamental não esquecer que é uma EF corpórea aquela a que nos estamos a referir - uma $E F$ que nos ajude a situar as formas em que pensamos, pelas quais sentimos e nos movemos e que nos permita compreender e interpretar os movimentos dos nossos corpos em relação com os sistemas e estruturas culturais, nos quais estes significados são criados 
e questionados ${ }^{(9)}$. A EF parece providenciar uma óptima oportunidade para uma atenção detalhada à disciplinarização do corpo e da produção de subjectividades incorporadas. É a disciplina curricular principalmente preocupada com o 'trabalho' no corpo, com a regulação e controlo do corpo através de práticas desportivas ritualizadas (20). Se, conforme argumenta Amour(1), o trabalho do corpo (body-work) é a razão primária a ter em conta pelos/as docentes no currículo escolar, então parece-nos essencial que, como educadores/as e professores/as de EF, devemos prestar atenção aos tipos de trabalho do corpo que alimentamos e às formas corpóreas que transmitimos(41). E porque o que está em causa é a educação e a aprendizagem, a EF deve ser sentida por todos e todas como uma experiência positiva e importante na vida, deve proporcionar a rapazes e raparigas experiências que não tenham como eixo orientador estereótipos de género(5).

Importa estudar as múltiplas vertentes em que as questões de género codificam e estruturam comportamentos e vivências de rapazes e raparigas nas actividades desportivas. Neste estudo pretende-se conhecer as percepções de alunos e alunas acerca das relações de género nas aulas de EF no ensino secundário, particularmente como eles e elas classificam essas relações e em que fundamentam a sua opinião.

\section{MATERIAL E MÉTODOS}

Nem tudo podemos observar, não conseguimos observar sentimentos, pensamentos e intenções. Também não conseguimos observar como cada um/a organiza o seu mundo e os significados que vai dando ao que vai acontecendo. Para isso temos que colocar questões. A entrevista, enquanto procedimento de uma metodologia qualitativa, parte do princípio que a perspectiva dos/as outros/as é passível de ser conhecida, pode ser explicitada e tem um significado(23). A entrevista permite aferir o que uma pessoa sabe (informação ou conhecimento), daquilo de que gosta e de que não gosta (valores e preferências) e o que pensa (atitudes e crenças) (33). No presente estudo foram realizadas entrevistas a estudantes do ensino secundário, que permitiram o acesso a opiniões, atitudes, percepções, representações e conhecimentos acerca da disciplina de EF. Tratandose de estudantes do ensino secundário, a vivência da disciplina durante o ensino básico e agora no ensino secundário possibilitou a estruturação de uma opinião acerca da disciplina e o desenvolvimento de afectos, estigmas, repulsas, ou estereotipias para com a EF. A recolha de dados fez-se através da realização de entrevistas semi-estruturadas a 60 estudantes (30 de cada sexo) de escolas do distrito do Porto, com idades compreendidas entre os 15 e os 17 anos, tendo sido obtido antecipadamente o consentimento informado de todos/as participantes. O guião das entrevistas, realizadas sempre pelo mesmo elemento da equipa de investigação, contemplou questões acerca das relações de género nas aulas de $\mathrm{EF}$ e das actividades desportivas e o género. Este estudo pretende conhecer como alunos e alunas classificam e entendem o desenvolvimento das relações de género nas aulas de EF.

As entrevistas foram gravadas em registo áudio com o assentimento de cada um/a dos/as participantes, transcritas na íntegra e formatadas para tratamento da informação no programa QSRNVivo. Procedeu-se a uma análise indutiva dos dados, ou seja, as categorias de análise não foram impostas num momento precedente à sua recolha e análise mas emergiram dos próprios dados. Findo o processo de tratamento dos dados, desenvolveu-se uma análise interpretativa. Este tipo de análise assume um lugar crucial neste estudo, e em qualquer estudo que decorra no contexto de ensino-aprendizagem, porque ajuda a expor o que nem sempre é óbvio, a tornar visível o que está oculto( 26,42$)$, nomeadamente, trazer à consciência e suscitar a reflexão sobre um conjunto de significados e práticas na $E F$, no que diz respeito às relações de género. Todos os nomes utilizados no texto são pseudónimos para assegurar o anonimato dos/as participantes.

\section{APRESENTAÇÃO E DISCUSSÃO DOS RESULTADOS}

As relações, comportamentos e atitudes de género na $E F$

No que respeita à percepção que os/as discentes têm acerca das relações de género no âmbito das aulas de EF, $64 \%$ dos/as entrevistados/as consideram-nas boas. Apesar da percentagem de discentes que percepcionam um mau relacionamento $(36 \%)$ constituir, por si só, um factor preocupante, quando nesta análise, meramente numérica, apartamos rapazes de raparigas, os dados impõem uma leitura que não 
deve cingir-se unicamente a uma análise quantitativa. Pela análise dos dados verificamos que rapazes e raparigas percepcionam e qualificam diferentemente as relações de género que se desenvolvem nas aulas de EF. Com efeito, $50 \%$ das raparigas percepcionam a existência de más relações, enquanto $79 \%$ dos rapazes entrevistados entendem existirem boas relações entre rapazes e raparigas nas aulas de EF. Os rapazes que pensam que existe um mau relacionamento $(21 \%)$ suportam essa classificação na preferência de formação de grupos não mistos para a execução das tarefas da aula.

(silêncio) Costumam ser grupos, jogam rapazes com rapazes e à parte as raparigas. Não costumam ser mistos ou porque há rapazes que, se calhar, não querem porque elas não dão o mesmo que eles, ou elas não querem porque os rapazes se jogarem mais que elas...(...) É separado. [José:secção6, parágr.52-54]

As alunas que percepcionam um mau relacionamento $(50 \%)$ são bastante claras quanto às situações nas quais baseiam esse seu juízo.

Por exemplo, quando estamos a jogar volei os rapazes não nos dão assim muitas oportunidades para, uma bola vem na nossa direcção e eles põem-se logo no nosso lugar, não respeitam as colocações. [Maria:seç̧ão7, parágr.52]

..., e acho que quando se joga futebol ou outras coisas os rapazes põem de parte um bocado as raparigas, eu pelo menos sinto isso. [Joana:secção5, parágr.57]

A gente bem que diz 'passem a bola, passem a bola', mas jogam entre eles, não há hipótese. Por isso nós ficamos um bocadinho... [Dulce:seç̧ão6, parágr.103]

... quando temos equipas mistas nota-se que, por exemplo, eles se nós perdemos uma bola, se nós fazemos alguma coisa mal, eles vêm em cima de nós, porque afinal a equipa é mais fraca porque tem raparigas, e vêem-nos às vezes como mais fracas e não tão capazes como eles. [Rita:seç̧ão6, parágr.67]

Por exemplo, os rapazes, pronto, é aquela coisa, eles acham que sabem mais que nós. Se nós cometemos algum erro eles começam logo a dizer "ai não faças assim", não sei o quê. Se forem eles a cometer um erro nós não dizemos nada, (...) Comę̧am logo a resmungar connosco, não sei o quê. Depois nós comę̧amos a, pronto, ficamos nervosas e só fazemos asneiras mesmo. [Filipa :secção5, parágr.57-61] Há certos rapazes que não gostam, ui!!! Quando dizem "jogar com as raparigas": "uиuu" qualquer coisa. [Raquel:secção6, parágr.47]
As descrições aqui apresentadas constituem queixas recorrentes, que expressam, sem margem para dúvidas, que as raparigas são sujeitas a comportamentos e atitudes ofensivas por parte dos seus colegas rapazes. Comportamentos ofensivos, depreciativos, que criam sentimentos negativos e desconfortáveis na pessoa, ou no grupo de pessoas, a quem se dirigem. Não está aqui em questão o que desencadeia este tipo de comportamentos e se quem os apresenta os entende como ofensivos ou abusivos da sua suposta posição de superioridade (neste caso, a de sentir-se mais capaz no desempenho de determinadas habilidades desportivas); o importante é apontar o efeito desse comportamento na outra pessoa. São comportamentos de género que, por ignorarem a sua presença nas actividades e/ou pelos comentários depreciativos aquando da sua participação, impedem e/ou afastam as raparigas das práticas desportivas nas aulas.

Algumas das alunas, que consideram existir boas relações, também descrevem situações similares. Porque é assim, ninguém gosta de perder, não é, e as raparigas normalmente têm menos jeito. E os rapazes começam: "ai, não sei o quê, faz para aqui faz para ali", e eu não gosto [Catarina:seç̧ão6, parágr.66].

...por exemplo, em equipas mistas vamos jogar futebol, - é muito raro um rapaz passar uma bola a uma rapariga. Estamos nas equipas mas ficamos de parte, estamos ali só para marcar presença. [Sara:secção6, parágr.59]

Acho que os rapazes tentam, eles podem gozar um bocado, "ah não tens jeito nenhum, mas anda lá..." mas motivam, pelo menos, não nos põem assim à parte. [Ana:seç̧ão6, parágr.60]

Eles até são vistos como condescendentes com eventuais desempenhos inferiores das suas colegas em tarefas de extensão ou de refinamento, mas impedem-nas de desempenharem as acções de jogo ou de finalizarem quando colocadas em situação favorável a tal porque aqui, em tarefas de aplicação, em situações de jogo, com a presença de uma vertente competitiva, elas terem a bola significa para eles que o êxito está em risco.

As raparigas têm a percepção clara de que os rapazes vêem a sua presença na equipa ou no grupo como um problema, intimidando-as e criticando os seus esforços ${ }^{(10)}$. Elas declaram o seu desagrado pelo comportamento de muitos dos seus colegas da 
turma: são comportamentos, atitudes e/ou interacções em que elas não são tratadas com respeito e potenciais geradores de um ambiente educativo vazio de igualdade e justeza.

A frequente vivência por parte das raparigas de situações de ridicularização e ofensivas durante as aulas parece influenciar a relação e a participação

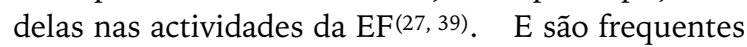
as queixas das alunas entrevistadas em relação a comportamentos e atitudes dos seus colegas rapazes. Elas sentem-se marginalizadas, impedidas de participarem ou mesmo ridicularizadas nos seus esforços e desempenhos.

As oportunidades de prática desportiva, de desenvolvimento motor e participação das raparigas dentro do espaço da aula parecem estar condicionadas pelas atitudes e comportamentos de género dos rapazes. Acho que eles não deviam ser tão machistas, deviam darnos mais oportunidades, mas não. É sempre a mesma coisa. [Filipa:secção6, parágr.76]

Uma referência frequente nas opiniões das raparigas é o machismo dos seus colegas, ou seja, o conjunto de comportamentos e crenças que justificam e promovem a manutenção de atitudes discriminatórias para com as raparigas/mulheres, tendo como base o princípio de que eles lhes são superiores. O machismo foi, e continua a ser, um elemento de controlo social numa cultura sexista. O machismo pósmoderno é um novo fenómeno que se alimenta da velha cultura patriarcal e a rediz e inova nos 'vícios' e 'compulsões' da sociedade pós-tradicional $(15,16)$. Mas estes comportamentos dos alunos parecem ter efeitos para além das resistências que colocam a uma participação das raparigas nas actividades desportivas nas aulas de EF, problema que tem que ser gerido por elas - eles são, também, incentivadores de um desinvestimento das alunas nas práticas desportivas.

por exemplo, jogar futebol, "Ah, as raparigas vão jogar?" Já torcem o nariz, (...) pronto e acho que eles são um bocado machistas nesse aspecto... e acho também que fazem com que as raparigas deixem de gostar de desporto mesmo por causa deles. [Leonor:seç̧ão6, parágr.99]

A investigação vem repetidamente alertando que as raparigas e as mulheres afastam-se da actividade desportiva em vários estádios da sua vida, sendo, frequentemente, apontadas como 'o problema' - par- ticularmente no contexto da $\mathrm{EF}$, em que muitas das práticas estão profundamente genderizadas - pelos seus pobres reportórios de habilidades motoras, pelas suas frequentes atitudes de relutância para se empenharem e por serem menos competitivas $(11,36$, $37,38,39)$ nas actividades que são geralmente valorizadas no currículo, ou seja, os jogos desportivos tradicionais ${ }^{(41)}$.

Tendo em atenção 'os problemas' vividos pelas raparigas na $\mathrm{EF}$ e a sua frequente resistência em participar nas actividades desportivas escolares, começouse a duvidar do ambiente 'coeducativo' das turmas mistas em EF, comparando-o a um simples convite endereçado às raparigas para participarem numa $\mathrm{EF}$ de e para rapazes ${ }^{(35)}$. Com efeito, as raparigas parecem poder melhorar os seus níveis de participação e os seus desempenhos em aulas de EF com ambientes separados por sexos - por estes se apresentarem como mais promotores para a aprendizagem, mais seguros e prazenteiros para a participação das alunas nas actividades desportivas (39). Embora estes ambientes segregados se afigurem como importantes facilitadores dos ganhos de confiança das alunas, a questão que deve ser colocada é se este ganho de confiança será mantido enquanto a percepção dos rapazes acerca das capacidades e habilidades das raparigas e os seus comportamentos para com elas não se alterarem. O que se afigura é que estes ambientes segregados são também espaços onde formas de uma masculinidade hegemónica são valorizadas, e onde os rapazes menos hábeis ou com uma menor relação com o desporto são marginalizados ou mesmo agredidos ${ }^{1}$. Além disto, parecem ser ambientes propícios a interacções entre alunos e professores que não questionam a percepção dos jovens acerca do seu domínio sobre as raparigas em habilidades e conhecimentos desportivos $(39,40)$. Juntar os alunos e as alunas nas aulas de EF, só por si, não leva, necessariamente, a alguma alteração de como o desporto interfere nos tácitos processos de transição de rapaz para homem numa sociedade dominantemente gerida e orientada por homens(18), ou seja, na formação de uma masculinidade hegemónica do jovem numa sociedade tipicamente androcêntrica.

A questão então subsiste: um ambiente segregado por sexos nas aulas contempla as questões da ridicu- 
larização e assédio baseado no género e das relações de poder que se operam entre homens e mulheres? Ou estas questões também estão aí contidas? (40). Ciente de que uma EF mista não contempla as necessidades das raparigas, Patricia Vertinsky(35) defende um modelo, que designa de coeducativo pelo seu maior potencial de permitir desafiar valores culturais, identidades de género e estereótipos de género associados ao desporto. A EF deve, no seu entender, procurar formas de intervenção sensíveis ao género nas quais os/as docentes têm um importante papel. Estes/as devem colocar no centro das suas atenções as questões de género, sendo explícitos/as no seu ensino acerca da construção social de género no sentido de tentarem alcançar uma real equidade. Não se nega aqui que, em determinados contextos, em determinados momentos, a separação baseada nos sexos nas aulas de EF não se afigure como uma estratégia produtiva, no entanto devem ser consideradas as suas consequências se entendida a sua utilização de forma sistemática e a longo prazo(40).

\section{As preferências de género no trabalho em grupo na $E F$} Os processos de interacção social observados fazem parte da EF perspectivada como uma comunidade de prática. Cada situação contribui para manter ou desafiar as normas, regras, convenções, identidades, etc., dentro da aula. As estruturas e as interacções num contexto social influenciam as trajectórias da aprendizagem de cada pessoa de forma diferente, parecendo óbvio que o tempo e a história desempenham um papel importante - a próxima aula nunca será igual, mas estará impressa pelas acções e exemplos da aula anterior (26).

O que parece influenciar na estruturação da relação entre géneros nas aulas de EF é a maneira como cada discente se posiciona em relação ao outro género. Isto no que respeita às percepções acerca das suas capacidades e habilidades motoras e acerca das que atribui às pessoas do outro género. Estes juízos de valor parecem condicionar as predisposições para trabalhar em grupos mistos. Assim, as raparigas ou se refugiam em grupos do seu sexo para evitarem ser sujeitas a comportamentos e/ou atitudes desagradáveis por parte dos seus colegas rapazes, ou preferem os grupos mistos que lhes proporcionam níveis de empenhamento superior e maior competitividade. As raparigas que jogam melhor preferem jogar em equipas mistas porque entendem que o jogar com e contra os rapazes adiciona competitividade ao jogo e proporciona mais desafios ${ }^{(37)}$. No âmbito das aulas de EF, do total de discentes entrevistados/as, 53\% afirmaram preferir trabalhar com elementos do mesmo sexo, $18 \%$ mostraram preferência por o fazer com elementos do sexo oposto e a $25 \%$ era-lhes indiferente.

Algumas das alunas (30\%) preferem formar grupo com um colega; um número mais elevado de alunos (55\%) escolhe colegas do mesmo sexo. Embora com objectivos algo diferentes, estas alunas e estes alunos entendem ser mais fácil alcançá-los se trabalharem com um rapaz - para elas o objectivo é melhorar o desempenho; para eles o conseguirem ser mais competitivos.

Acho que eu, se calhar, num exercício consigo fazer melhor e puxar mais por mim se for com um rapaz do que com uma rapariga. [Leonor:secção6, parágr.107]

Costumo trabalhar com... (pausa), eu sinceramente costumo trabalhar com os rapazes porque acho que trabalho mais, puxam mais por mim do que as raparigas. As raparigas fazem o que têm a fazer mas não dão o seu melhor. [Joana:seç̧ão6, parágr.72]

Porque, prontos, nós quando vamos fazer uma coisa, eles são melhores. Se jogarmos com uma pessoa que jogue tanto ou pior que nós, nós não conseguimos evoluir. (...) Estamos sempre naquele nivel. E eles dizem "faz isto assim, faz isto assim", e nós evoluirmos. [Sara:secção6, parágr.67-69] (quando trabalha com um rapaz procura) o empenho da parte dele e o meu empenho em vencê-lo (...) (Acho que melhoro mais..) com um rapaz. Tenho que dar muito mais de mim do que com uma rapariga. [Mafalda:secção5, parágr.66-69]

Dá mais gozo, no sentido de conseguir realizar melhor com eles do que com elas.(...) Uma pessoa não se sente tão motivado, e não existe assim uma rivalidade tão forte, $e$ com um rapaz dá mais gozo, dá mais gosto.

Uma pessoa não se sente tão motivado, e não existe assim uma rivalidade tão forte, e um rapaz dá mais gozo, dá mais gosto e é...(...) Dá mais luta, é isso. [Mário:secção6, parágr.76-80]

Não sei, é por causa da competitividade. (...) Certos desportos, acho que é melhor, para melhorar. (...) há uma competitividade maior. [David:secção6, parágr.76-80] 
O que transparece nestes discursos é a vontade de melhorar, de conseguir melhores desempenhos, e para tal é crucial ter alguém que obrigue a um maior esforço, a uma superação individual. E, tanto para alunos como para alunas com esses objectivos, a parceria ideal é com um rapaz. Para elas a vertente predominante é a melhoria das suas performances, para eles além dessa vertente emerge outro elemento que justifica as suas preferência por grupos com elementos do mesmo sexo, a competitividade.

Algumas destas particularidades do discurso dos rapazes persistem na opinião dos alunos que referiram que era indiferente o trabalharem com rapazes ou com raparigas:

É indiferente. (...) o que eu posso dizer é que se forem equipas mistas é mais, pronto, se forem só rapazes é mais competição, isso não há dúvida.

(...) Imagine um jogo de basquetebol, se forem só rapazes lá está, não temos o cuidado que temos a jogar com as raparigas, pode haver mais contacto físico, e há mais competição. Com as raparigas pronto, é mais... [Nuno:seç̧ão6, parágr.61-65]

As alunas que referem preferir trabalhar com elementos do mesmo sexo (50\%) fazem-no porque parece ser o mais usual, ou porque se sentem mais "à vontade".

Sempre foi assim. Nunca escolhi um rapaz para trabalhar. [Liliana:secção4, parágr.58]

Raparigas. Por acaso é, por acaso é. Lá está, eles ligam-se logo rapazes e nós também ficamos com raparigas.

[Rita:secção6, parágr.69]

Com raparigas, sinto-me mais à vontade. [Marta:secção6, parágr.71]

Com uma rapariga porque me sinto mais à vontade. Por exemplo na minha turma a maioria dos rapazes praticam futebol então eu não me sinto à vontade em jogar com eles. (Mas se a modalidade não for o futebol? No geral?) Mas prefiro fazer com uma rapariga, sinto-me mais à vontade. É mesmo assim. [Dulce:secção6, parágr.105-107] Com raparigas. Porque é assim, ninguém gosta de perder, não é, e as raparigas normalmente têm menos jeito. E os rapazes começam: "ai, não sei o quê, faz para aqui faz para ali”, e eu não gosto. [Luísa:seç̧ão6, parágr.64-66] O que aqui parece estar implícito é que as raparigas se sentem mais confortáveis se o seu par for uma rapariga para o desempenho das tarefas nas aulas de EF. A última fala aqui apresentada parece trazer à luz o que as restantes omitem ou escondem nas justificações do 'sinto mais à vontade' - leva-nos a supor que, eventualmente, à perspectiva de trabalhar com rapazes, mesmo considerando boas as relações com eles no âmbito das aulas, vem associado um visionamento de momentos desagradáveis.

A EF continua a ser genderizada na ideologia, nos seus conteúdos e nas suas relações com outros espaços de cultura desportiva ${ }^{(6,29)}$, parecendo existir pontos de disjunção entre os valores e práticas da EF e aqueles que as raparigas procuram em outros espaços de prática desportiva(14,37).

No contexto da EF, é comummente entendido que uma equidade de oportunidades se cumpre quando as raparigas e os rapazes têm as mesmas oportunidades $(28,29)$, resumindo-se estas oportunidades ao terem oportunidades de acesso. Isto é, se raparigas e rapazes tiverem iguais oportunidades de 'acesso a', então parece estar contemplada uma igualdade de género. Assim, numa escola que se intitula promotora de iguais oportunidades para rapazes e raparigas, misturam-se alunos e alunas numa mesma turma tentando que as raparigas se adaptem a currículos e conteúdos programáticos concebidos e desenhados para o público-alvo de origem, os rapazes. As raparigas têm iguais oportunidades numa EF 'masculina', onde são consideradas menos hábeis, menos capazes fisicamente e menos interessadas(27). Parece não ser controverso que esta cultura da masculinidade no desporto e na EF teve impactos negativos na participação das raparigas (35). Além de tudo, o ambiente misto nas aulas de EF é propício a que as raparigas sejam marginalizadas pelos comportamentos dos rapazes e, com frequência, por eles ridicularizadas (27).

No âmbito deste estudo podemos concluir que: - são, principalmente, as alunas (50\%) que percepcionam as relações entre rapazes e raparigas como não sendo boas nas aulas de EF;

- algumas alunas queixam-se de comportamentos e atitudes dos seus colegas que as incomodam, as ofendem e as levam a um desinvestimento nas actividades;

- a tendência é os/as estudantes preferirem trabalhar nas actividades das aulas de EF com colegas do mesmo sexo; eles porque entendem que dessa forma conseguem a presença da competitividade no desen- 
volvimento das actividades, elas porque é o usual e, para algumas, é a forma que anula as hipóteses de serem importunadas;

- uma percentagem considerável de alunas (30\%) prefere trabalhar com rapazes por considerarem que têm que se empenhar, esforçar mais e sentem que melhoram os seus desempenhos.

Rapazes e raparigas são bem explícitos/as na demonstração de que as questões do género e das relações de género invadem os espaços educativos, estão presentes no contexto das aulas de EF e influenciam as suas práticas desportivas.

\section{CORRESPONDÊNCIA}

\section{Paula Silva}

Faculdade de Desporto

R. Dr. Plácido Costa, 91 4200-450 Porto, Portugal

E-mail: psilva@fade.up.pt

\section{NOTA}

${ }^{1}$ Aqui no sentido do termo de origem inglesa bullying, entendido como um aluno ou uma aluna ser exposto, repetida e continuadamente, a acções negativas por parte de um ou mais colegas que ocorrem num relacionamento onde há um desequilíbrio de poder entre as partes envolvidas (Olweus, 2000). As raparigas são, com maior frequência, vítimas de agressões indirectas enquanto os rapazes são mais frequentemente vítimas de agressões físicas e de ameaças (Pereira et al., 1996). 


\section{REFERÊNCIAS BIBLIOGRÁFICAS}

1. Amour Kathleen (1999). The case for a body-focus in education and physical education. Sport, Education and Society 4(1), 5-15.

2. Bento Jorge (1995). O outro lado do desporto. Porto: Campo de Letras.

3. Bento Jorge (2001). Da Legitimação da Educação Física. Educação Física. Coleção Prata da Casa 11, 9-32.

4. Bento Jorge (2004). Desporto para Crianças e Jovens: Das Causas e dos Fins. In Adroaldo Gaya, António Marques e Go Tani (orgs.), Desporto para Crianças e Jovens. Razões e Finalidades (pp.21-56). Porto Alegre: Editora da UFRGS.

5. Botelho Gomes Paula (2001) Educação Física e Desporto na Escola: razões para um novo contrato didáctico. Coleção Prata da Casa 11, 53-80.

6. Brown David, Rich Emma. (2002). Gender positioning as pedagogical practice in teaching physical education. In D. Penney (Ed.), Gender and Physical Education. Contemporary Issues and Future Directions (pp. 80-100). London and New York: Routledge.

7. Connell Robert (1990). An Iron Man: The Body and Some Contradictions of Hegemonic Masculinity. In Michael A. Messner, Donald F. Sabo (Eds.), Sport, Men and Gender Order (pp. 83-96). Champaign, Il: Human Kinetics.

8. Connell Robert (2002). Gender. Cambridge: Polity Press.

9. Dewar Alison (1993). Would all the generis women in sport please stand up?: Challenges facing feminist sport sociology. Quest 45: 211-229.

10. Ennis Catherine (1999). Creating a Culturally Relevant Curriculum for Disengaged Girls. Sport, Education and Society 4(1): 31-49.

11. Evans John, Davies Brian, Penney Dawn (1996). Teachers, Teaching and the Social Construction of Gender Relations. Sport, Education and Society 1(2): 165-184.

12. Fasting Kari, Scraton Sheila, Pfister Gertrud, Bunuel Ana. Summary of "The Experience and Meaning of Sport and Exercise in the Lives of Women in Some European Countries. [On-line]: www.icsspe.org/portal/texte/project/tx2110.html

13. Flax Jane (1990). Postmodernism and Gender Relations in Feminist Theory. In Linda J. Nicholson (Ed.), Feminist/Postmodernism (pp. 39-62). New York: Routledge.

14. Garrett Robyne (2004). Gendered bodies and physical identities. In J. E. B. D. J. Wright (Ed.), Body Knowledge and Control. Studies in the sociology of physical education and health (pp. 140-156). London and New York: Routledge.

15. Giddens Anthony (1991). As consequências da modernidade. Unesp, São Paulo.

16. Giddens Anthony (1995). A vida em uma sociedade póstradicional, pp. 73-134. In A Giddens, U Beck \& A Lasch (orgs). Modernização reflexiva. Editora Unesp, São Paulo.

17. Giddens Anthony (1997). Modernidade e Identidade Pessoal. Oeiras: Celta Editora.

18. Griffin Patricia (1989). Gender as a Socializing Agent in Physical Education. In T. J. T. P. G. Schempp (Ed.), Socialization into Physical Educational: Learning to Teach (pp.219-234). Indianapolis : Benchmark Press.

19. Harding Sandra (1991). Whose Science? Whose Knowledge? Thinking from Women's Lives. New York: Cornell University Press.

20. Hargreaves Jennifer (1986). The Social Production of Gender Through Sport. Theory, Culture and Society 3(1):
114-119.

21. Louveau Catherine (2001). Desporto, mulheres, media: o corpo desejável das desportistas. ex aquo 4: 57-74.

22. Olweus Dan (2000). Bullying at School. Oxford: Blackwell Publishers, Ltd.

23. Patton, M. (2002). Qualitative Research \& Evaluations Methods. Thousand Oaks: Sage.

24. Pereira Beatriz, Almeida Ana, Valente Lucília, Mendonça Denise (1996). O bullying nas escolas portuguesas: análise das variáveis fundamentais para a identificação do problema. In Almeida, Silvério e Araújo (Org.), Actas do II Congresso Galaico-Português de Psicopedagogia da Universidade do Minho. Braga: Universidade do Minho.

25. Pfister Gertrud (2003, June). Sport and socialisation - a gender perspective. Paper presented at the seminar of the Summer School Sport and Gender. University of Copenhagen, Copenhagen.

26. Ronholt Helle (2002). 'It's Only the Sissies...': Analysis of Teaching and Learning Processes in Physical Education: A contribution to the Hidden Curriculum. Sport, Education and Society $7(1): 25-36$.

27. Scraton Sheila (1993). Equality, Coeducation and Physical Education in Secondary Schooling. In J. Evans (Ed.), Equality, Education and Physical Education. Lewes: Falmer Press.

28. Talbot Margaret (1990). Equal Opportunities and Physical Education. In N. Armstrong (Ed.), New Directions in Physical Education (pp.101-120). Champaign, IL: Human Kinetics Books.

29. Talbot Margaret (1993). A gendered physical education: equality and sexism. In J. Evans (Ed.) Equality, Education and Physical Education (pp. 74-89). London: Falmer Press.

30. Theberge Nancy (1987). Sport and women's empowerment. Women's Studies International Forum 10: 387-393.

31. Theberge Nancy (1991). Reflections on the body in the sociology of sport. Quest 43(2): 123-134.

32. Theberge Nancy (1994). Toward a Feminist Alternative to Sport as a Male Preserve. In S. Birrell; C.L. Cole (Eds.), Women, Sport, and Culture (pp.181-192). Champaign, IL: Human Kinetics.

33. Tuckman Bruce (2000). Manual de Investigação em Educação. Lisboa: Fundação Calouste Gulbenkian.

34. Vale de Almeida Miguel (2004). O Manifesto do Corpo. manifesto 5: 18-35.

35. Vertinsky Patricia (1992). Reclaiming Space, Revisioning the Body: The Quest for Gender-Sensitive Physical Education. Quest 44(3): 373-396.

36. Williams Anne (1993). Who cares about girls? Equality, physical education and the primary school child. In J. Evans (ed.), Equality, Education and Physical Education (pp. 125-138). London: Falmer Press.

37. Williams Anne, Bedward Julie (2002). Understanding girls' experience of physical education: situational analysis and situated learning. In Dawn Penney (Ed.) Gender and Physical Education: Contemporary Issues and Future Directions (pp. 146-159). London: Routledge.

38. Williams Anne, Bedward Julie, Woodhouse J (2000). An inclusive curriculum? The experience of adolescent girls. European Journal of Physical Education 5(1): 4-18.

39. Wright Jan (1996). The Constrution of Complementarity in Physical Education. Gender and Education 8(1): 61-79.

40. Wright Jan (1999). Changing Gendered Practices in 
Physical Education: Working with Teachers. European

Physical Education Review, 5(3), 181-197.

41. Wright Jan. (2000). Bodies, Meanings and Movement: A Comparison of the Language of a Physical Education Lesson and Feldenkrais Movement Class. Sport, Education and Society 5(1): 35-49.

42. Wright Jan, King RC (1991). "I say what you mean" said Alice: An analysis of gendered discourses in physical education. Journal of Teaching in Physical Education 10: 210-225. 